\title{
Expression of Zinc Finger and BTB Domain-containing 7A in Colorectal Carcinoma
}

\author{
JIN WOO JOO ${ }^{1}$, HYUN-SOO KIM ${ }^{1}$, SUNG-IM DO ${ }^{2}$ and JI-YOUN SUNG ${ }^{3}$ \\ ${ }^{1}$ Department of Pathology, Severance Hospital, Yonsei University College of Medicine, Seoul, Republic of Korea; \\ ${ }^{2}$ Department of Pathology, Kangbuk Samsung Hospital, \\ Sungkyunkwan University School of Medicine, Seoul, Republic of Korea; \\ ${ }^{3}$ Department of Pathology, Kyung Hee University School of Medicine, Seoul, Republic of Korea
}

\begin{abstract}
Background/Aim: Previous studies have revealed that zinc finger and BTB domain-containing 7A (ZBTB7A), an important proto-oncogene, plays multiple roles in carcinogenesis and is up-regulated in several human malignancies. However, the expression of ZBTB7A in colorectal carcinoma (CRC) has seldom been documented. In this study, we investigated the differential expression of ZBTB7A in CRC cell lines and tissues. Materials and Methods: Expression levels of ZBTB7A mRNA and protein were examined in CRC cell lines. ZBTB7A protein expression was also evaluated in tissue samples of normal colonic mucosa, high-grade dysplasia, and CRC using immunohistochemical staining. Results: All CRC cell lines exhibited significantly higher ZBTB7A mRNA expression levels than did normal colonic epithelial cells. The $Z B T B 7 A$ protein expression levels were clearly higher in the $C R C$ cell lines than in the normal colonic epithelial cells. Consistent with the cell line data, immunostaining revealed that there were significant differences in ZBTB7A protein expression between tissue samples of CRC and normal colonic mucosa $(p=0.048)$ and high-grade dysplasia $(p=0.015)$. In addition, metastatic CRC exhibited significantly higher ZBTB7A protein expression levels than primary CRC $(p=0.027)$. Conclusion: We demonstrated that ZBTB7A expression is up-regulated in CRC cell lines and tissues. Our data suggest that ZBTB7A is involved in the development and progression of CRC.
\end{abstract}

Colorectal carcinoma (CRC) is one of the most prevalent forms of malignancies worldwide, with over 600,000 CRC-related

Correspondence to: Hyun-Soo Kim, Department of Pathology, Severance Hospital, Yonsei University College of Medicine, 50-1 Yonsei-ro, Seodaemun-gu, Seoul 03722, Republic of Korea. Tel: +82 222281794, +82 23620860, e-mail: hyunsookim@yuhs.ac

Key Words: Colon, colorectal carcinoma, zinc finger and BTB domain-containing 7A, leukemia/lymphoma-related factor, poxvirus and zinc finger and Krüppel erythroid myeloid ontogenic factor. deaths occurring annually (1). It is the second leading cause of cancer-related deaths in Europe and North America, and the fourth most common type of cancer in Western countries (1, 2). In the Republic of Korea, CRC is the third most common type of cancer and the fourth leading cause of cancer-related deaths (3). The carcinogenesis of CRC involves complex processes, with multiple factors and stages. The detailed mechanisms of action of CRC-related proto-oncogenes and tumor suppressors remain unclear (4). Up-regulation of certain proto-oncogenes or loss of certain tumor suppressors are involved in the development and progression of CRC. Aberrant expression of genes and proteins appears to influence the oncogenic behavior and dictate the likelihood of the response to therapeutic agents. It is therefore important to describe accurately the histopathological, immunohistochemical, and molecular features of tumors that may affect the treatment decisions of oncologists and surgeons (5).

Zinc finger and BTB domain-containing 7A (ZBTB7A), also known as a factor that binds to the inducer of short transcripts of human immunodeficiency virus type 1 , leukemia/lymphomarelated factor, osteoclast-derived zinc finger, and pokemon, is a member of BTB/poxvirus and zinc finger and Krüppel (POK) family transcription factors. Through the zinc finger domain, POK proteins bind to a specific consensus sequence in the target gene promoter to regulate its transcription. The BTB domain enables homodimer formation and interaction with co-repressor proteins such as the B-cell lymphoma 6 co-repressor, silencing mediators of retinoid and thyroid receptors, and $\mathrm{mSin} 3 \mathrm{~A} /$ histone deacetylase, which contribute to the transcriptional repressor function of POK proteins $(6,7)$. For ZBTB7A, the BTB domaininteracting proteins include B-cell lymphoma 6 , specificity protein 1 , and the androgen receptor (7). As a transcription factor that has a nuclear localization signal at the C-terminus, ZBTB7A has been predominantly detected in the nucleus (8-13). mRNA and protein expression of ZBTB7A has been detected in neoplastic tissues of multiple organs. Elevated ZBTB7A expression has been reported in diffuse large B-cell lymphoma and in carcinomas of the breast, lung, stomach, liver, ovary, and 
prostate $(9,10,12,14-16)$. The aberrant overexpression of ZBTB7A in human malignancies indicates that this protein may be involved in oncogenic transformation and tumorigenesis.

Recent studies have indicated that ZBTB7A has numerous functions, including the initiation of tumor formation by inhibiting tumor suppressors and by influencing several signal transduction pathways $(4,14,16)$. Despite its documented importance in other cancer types, only few studies have assessed ZBTB7A expression in CRC. Existing evidence for the important role of ZBTB7A in tumor development and progression prompted us to examine its expression in CRC. In this study, we investigated the expression of ZBTB7A in CRC cell lines and tissue samples.

\section{Materials and Methods}

Cell culture. Human normal colonic epithelial cell lines, FHC and CCD 841 CoTr, and human CRC cell lines, HT-29, HCT 116, SW480, SW620, DLD-1, and WiDr, were purchased from the American Type Culture Collection (Manassas, VA, USA). All cell lines were maintained in Dulbecco's modified Eagle's medium or Roswell Park Memorial Institute 1640 medium supplemented with $10 \%$ heatinactivated fetal bovine serum, penicillin $(100 \mathrm{U} / \mathrm{ml})$, and streptomycin $(100 \mu \mathrm{g} / \mathrm{ml})($ Gibco, Life Technologies, Grand Island, NY, USA) and were cultured at $37^{\circ} \mathrm{C}$ in a humidified atmosphere of $5 \% \mathrm{CO}_{2}$.

cDNA synthesis. Total RNA was isolated from the cell lines using the TRI reagent (Molecular Research Center, Cincinnati, OH, USA) and used for cDNA synthesis with a ReverTra Ace qPCR RT kit (Toyobo, Osaka, Japan). RNase-free DNase I treatment was carried out to remove contaminating genomic DNA from the purified total RNA. The isolated total RNA was diluted to $1 \mathrm{mg} / \mathrm{ml}$ with sterile diethylpyrocarbonate-treated water, and $2.5 \mathrm{ml}$ was added to reactions containing $1 \times$ DNase I buffer and $1 \mathrm{U}$ of DNase I (final volume, $10 \mathrm{ml}$ ). After incubation at $37^{\circ} \mathrm{C}$ for $30 \mathrm{~min}$, the reactions were terminated by heating at $70^{\circ} \mathrm{C}$ for $10 \mathrm{~min}$. The DNase I-treated RNA was reverse-transcribed into first-strand cDNA using random primers. DNase I-treated RNA ( $1 \mu \mathrm{g})$ and random primers $(250 \mathrm{ng})$ were mixed, and the volume was brought up to $11 \mathrm{ml}$ with sterile diethylpyrocarbonate-treated water. The mixture was heated at $65^{\circ} \mathrm{C}$ for $5 \mathrm{~min}$ and quickly chilled on ice. Other reagents were added to a $20-\mathrm{ml}$ reaction at the following final concentrations: $1 \times$ firststrand buffer, $10 \mathrm{mM}$ dithiothreitol, $0.5 \mathrm{mM}$ each dNTP, and $200 \mathrm{U}$ of Superscript II reverse transcriptase (Invitrogen, Carlsbad, CA, USA). The reactions were incubated at $42^{\circ} \mathrm{C}$ for $1 \mathrm{~h}$, then heated at $70^{\circ} \mathrm{C}$ for $10 \mathrm{~min}$, and the products were stored at $-20^{\circ} \mathrm{C}$. The amount of cDNA was determined spectrophotometrically.

Quantitative real-time polymerase chain reaction ( $q R T-P C R)$. The cDNA was used for qRT-PCR using the CFX96 real-time PCR detection system (Bio-Rad Laboratories, Hercules, CA, USA) with a C1000 thermal cycler (Bio-Rad Laboratories). PCR was carried out in a $20-\mu \mathrm{l}$ volume containing $0.3 \mu \mathrm{M}$ each primer, $10 \mu \mathrm{l}$ of $2 \times$ SsoAdvanced SYBR Green supermix (Bio-Rad Laboratories), and $3 \mu \mathrm{l}$ of template DNA. PCR for the ZBTB7A and $\beta$-actin genes was initiated with a denaturing step at $95^{\circ} \mathrm{C}$ for $3 \mathrm{~min}$, followed by 40 cycles at $95^{\circ} \mathrm{C}$ for $10 \mathrm{~s}, 60^{\circ} \mathrm{C}$ for $10 \mathrm{~s}$, and $72^{\circ} \mathrm{C}$ for $30 \mathrm{~s}$. The amplification data were analyzed, and the cycle threshold $(\mathrm{Ct})$ values were determined using CFX Manager software (Bio-Rad Laboratories). The primer sequences used for $Z B T B 7 A$ were as follows: forward, 5'-AGA AGA AGA TCC GAG CCA AGG-3'; reverse, 5'-TCA GCT TGT CCT GCC TGG T-3'. The $\Delta \Delta \mathrm{Ct}$ method was used to calculate the relative target gene expression after normalization to that of $\beta$-actin (17). Specificity of target gene amplification was confirmed by melting-curve analysis, and the target amplicon size was confirmed by agarose gel electrophoresis. Each sample was assayed in triplicate.

Western blot analysis. Whole-cell lysates were prepared in radioimmunoprecipitation assay buffer $(50 \mathrm{mM}$ Tris- $\mathrm{HCl}, \mathrm{pH} 8,150$ $\mathrm{mM}$ sodium chloride, $1 \% \mathrm{NP}-40,0.5 \%$ sodium deoxycholate, and $0.1 \%$ sodium dodecyl sulfate) containing protease inhibitors (Complete protease inhibitor cocktail tablet; Roche Applied Science, Basel, Switzerland) and cleared by microcentrifugation $(10,000 \times g$ for $20 \mathrm{~min}$ at $4^{\circ} \mathrm{C}$ ). The resulting lysate was assessed for the protein concentration, and 20-30 $\mu \mathrm{g}$ of each protein sample was resolved by $12 \%$ sodium dodecyl sulfate polyacrylamide gel electrophoresis (BioRad Laboratories) and electroblotted onto nitrocellulose membranes (GE Healthcare, Little Chalfont, UK). After 1-h incubation in a blocking solution (5\% non-fat milk in Tris-buffered saline with Tween 20; Pierce, Rockford, IL, USA), the membranes were incubated overnight at $4{ }^{\circ} \mathrm{C}$ with the following primary antibodies: anti-ZBTB7A (1:1,000; polyclonal; Cell Signaling Technology, Beverly, MA, USA) and anti- $\beta$-actin (1:5,000; Santa Cruz Biotechnology, Santa Cruz, CA, USA). The blots were washed three times with Tris-buffered saline with Tween 20 and then incubated with a horseradish peroxidaseconjugated secondary antibody (Cell Signaling Technology) for $1 \mathrm{~h} \mathrm{at}$ room temperature. Protein bands were visualized using an enhanced chemiluminescence reagent (iNtRON Biotechnology, Seongnam, Republic of Korea).

Tissue specimens. The study (2018-02-058) was reviewed and approved by the Institutional Review Board of the Kangbuk Samsung Hospital (Seoul, Republic of Korea). Tissue samples of CRC and high-grade dysplasia were obtained from 106 and 28 patients, respectively. Corresponding tissue samples from hepatic CRC metastases were obtained from 72 patients. Two independent Board-certified pathologists reviewed all hematoxylin and eosinstained slides and selected the most representative slide for each case for immunohistochemical staining. The 72 patients with hepatic metastases met the following criteria for hepatic resection with curative intent (18-21): medical fitness for major hepatic resection; colorectal liver metastasis that resulted in adequately sized, wellvascularized hepatic remnants after hepatic resection; and no signs of extrahepatic metastases in preoperative imaging studies, including chest radiography, abdominal ultrasonography, abdominopelvic computed tomography, and pelvic magnetic resonance imaging. No patient underwent preoperative neoadjuvant chemotherapy or neoadjuvant concurrent chemoradiation therapy.

Immunohistochemistry. Formalin-fixed tissues were dehydrated in a graded ethanol series and embedded in paraffin. Paraffin blocks were sectioned at $4 \mu \mathrm{m}$ using a standard rotary microtome, and slices were transferred from a water bath to cleaned slides. ZBTB7A protein expression was assessed by immunohistochemistry using a BOND polymer intense detection system (Vision BioSystems, Mount Waverley, Victoria, Australia) following the manufacturer's instructions. The general procedure has been described elsewhere (18- 

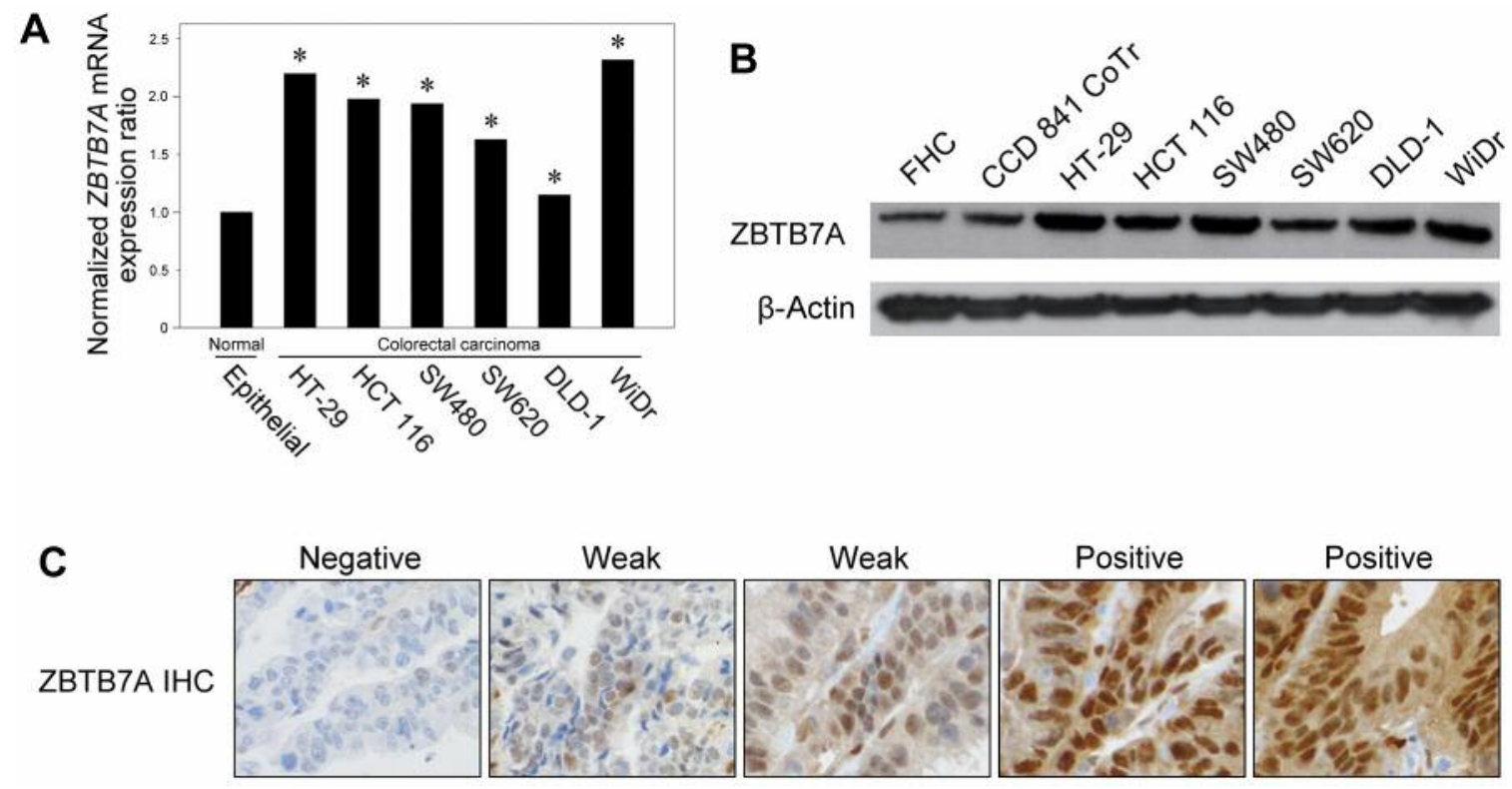

Figure 1. Expression of zinc finger and BTB domain-containing 7A (ZBTB7A) in colorectal carcinoma (CRC). Expression levels of ZBTB7A mRNA (A) and protein (B) in CRC cell lines (HT-29, HCT 116, SW480, SW620, DLD-1, and WiDr) and normal colonic epithelial cell lines (FHC and CCD 841 CoTr). *Significantly different from epithelial cell lines at $p<0.05$. C: ZBTB7A immunoreactivity in CRC tissue samples. Original magnification, $x 400$.

29). The 4- $\mu \mathrm{m}$ sections of formalin-fixed, paraffin-embedded tissue were deparaffinized with a BOND dewax solution (Vision BioSystems), and antigen retrieval was performed using BOND epitope retrieval solution (Vision BioSystems) for $30 \mathrm{~min}$ at $100^{\circ} \mathrm{C}$ Endogenous peroxidases were quenched with hydrogen peroxide for $5 \mathrm{~min}$. The sections were incubated for $15 \mathrm{~min}$ at ambient temperature with a rabbit polyclonal antibody to ZBTB7A (1:50; Novus Biologicals, Littleton, CO, USA). A biotin-free polymeric horseradish peroxidase-linker antibody conjugate system was used with a BondmaX automatic slide stainer (Vision BioSystems), and the visualization was performed using $1 \mathrm{mM} \mathrm{3,3'-diaminobenzidine,} 50$ $\mathrm{mM}$ Tris $-\mathrm{HCl}$ buffer ( $\mathrm{pH} 7.6$ ), and $0.006 \%$ hydrogen peroxide. The sections were counterstained with hematoxylin. The slides were dehydrated following a standard procedure and sealed with coverslips. To minimize the interassay variation, positive and negative control samples were included in each run. The positive controls were tissue samples of invasive ductal carcinoma of the breast. The negative control was prepared by substituting non-immune serum for the primary antibody so that no detectable staining was obvious.

Immunohistochemical evaluation. Immunohistochemical staining was independently analyzed by two pathologists who were blinded to the clinicopathological data. The ZBTB7A staining intensity was scored in tumor cells on a scale of $0-3$ : 0 , negative; 1 , weak; 2 , moderate; and 3, strong. The percentage of ZBTB7A-positive tumor cells was classified into one of the following four categories: 1,0 $24 \% ; 2,25-49 \% ; 3,50-74 \%$; and $4,75-100 \%$. The final score was calculated by multiplying the intensity score and the percentage score. ZBTB7A immunoreactivity was then classified as negative $($ score $=0)$, weak $($ score $=1-6)$, or positive $($ score $=8-12)$ expression . Disagreements between the two pathologists were resolved by discussion.
Statistical analysis. We used an unpaired Student's $t$-test to compare expression levels of ZBTB7A between the normal colonic epithelial and CRC cell lines. A chi-squared or Fisher's exact test was performed to compare ZBTB7A immunoreactivity among normal colonic mucosa, high-grade dysplasia, and CRC tissue samples. Statistical analyses were conducted using SPSS version 18.0 (SPSS, Inc., Chicago, IL, USA). Differences with $p$-values of less than 0.05 were considered statistically significant.

\section{Results}

Up-regulation of ZBTB7A expression in CRC cell lines. qRTPCR revealed significantly higher ZBTB7A mRNA expression in all CRC cell lines than that in the normal colonic epithelial cell lines (Figure 1A). Consistent with these findings, western blotting revealed that ZBTB7A protein expression was clearly higher in all the CRC cell lines than in the normal colonic epithelial cell lines (Figure 1B).

Up-regulation of ZBTB7A expression in CRC tissue samples. We investigated the ZBTB7A protein expression in CRC, highgrade dysplasia, and normal colonic tissue samples by immunohistochemistry. The differences in ZBTB7A expression among the groups are summarized in Table I. Representative photomicrographs of ZBTB7A immunostaining in CRC are shown in Figure 1C. In both dysplastic and malignant cells, ZBTB7A was predominantly located within the nuclei, although weak cytoplasmic staining was also detected. Weak to positive nuclear ZBTB7A immunoreactivity was observed 
Table I. Differences in immunoreactivity for zinc finger and BTB domain-containing 7A (ZBTB7A) among normal colonic mucosa, high-grade dysplasia, and colorectal carcinoma (CRC) tissue samples.

\begin{tabular}{|c|c|c|c|c|c|c|c|}
\hline \multirow[t]{2}{*}{ Type of tissue } & \multirow{2}{*}{$\begin{array}{c}\text { Number of } \\
\text { samples }\end{array}$} & \multicolumn{3}{|c|}{ ZBTB7A immunoreactivity, n (\%) } & \multicolumn{3}{|c|}{$p$-Value* } \\
\hline & & Negative & Weak & Positive & & & \\
\hline Normal colonic mucosa & 18 & $10(55.6)$ & $5(27.8)$ & $3(16.7)$ & & & \\
\hline High-grade dysplasia & 28 & $14(50.0)$ & $11(39.3)$ & $3(10.7)$ & $0.985^{\mathrm{a}}$ & & \\
\hline Primary CRC & 106 & $34(32.1)$ & $35(33.0)$ & $37(34.9)$ & $0.048^{\mathrm{a}}$ & $0.015^{\mathrm{b}}$ & \\
\hline Metastatic CRC & 72 & $15(20.8)$ & $20(27.8)$ & $37(51.4)$ & $0.002^{\mathrm{a}}$ & $<0.001^{\mathrm{b}}$ & $0.027^{\mathrm{c}}$ \\
\hline
\end{tabular}

${ }^{\mathrm{a}}$ Versus normal colonic mucosa; ${ }^{\mathrm{b}}$ versus high-grade dysplasia; ${ }^{\mathrm{c}}$ versus primary CRC. ${ }^{*}$ Significantly different at $p<0.05$.

in eight $(44.4 \%)$ out of the 18 normal colonic mucosal tissue samples, while in the remaining $10(55.6 \%)$ samples, ZBTB7A expression was not detected. The proportion of samples negative for ZBTB7A expression (50.0\%) among the highgrade dysplasia cases was similar to that among the normal colonic mucosa samples $(p=0.985)$. In contrast, $37(34.9 \%)$ and $35(33.0 \%)$ of the 106 primary CRC samples exhibited positive and weak ZBTB7A expression, respectively. The differences in ZBTB7A expression between the primary CRC tissues and normal colonic mucosa $(p=0.048)$, and high-grade dysplasia $(p=0.015)$ were statistically significant. Moreover, ZBTB7A expression in metastatic CRC was significantly higher than that in the primary CRC tissue samples $(p=0.027)$. More than half $(37 / 72,51.4 \%)$ of metastatic CRC cases exhibited positive nuclear ZBTB7A immunoreactivity.

\section{Discussion}

Depite major advances in surgical techniques and equipment as well as in chemotherapy and radiation therapy, the prognosis remains poor for patients with $\operatorname{CRC}(30,31)$. Traditionally, the prognosis has relied on pathological characteristics such as depth of invasion, nodal metastasis, and stage group. However, the current tumor-nodemetastasis classification system is limited in that it cannot offer a prognosis for individual patients (32). Selecting the most beneficial treatment regimen for CRC remains challenging because of the lack of predictive biomarkers for patient stratification (21). To improve the outcome for patients with $\mathrm{CRC}$, it is crucial to identify cancer-related genes that can serve as predictive and prognostic biomarkers to enable individualization of therapy. In this study, we first analyzed the mRNA and protein expression of ZBTB7A in CRC cell lines and found that the CRC cell lines exhibited elevated $Z B T B 7 A$ mRNA expression compared with that in the normal colonic epithelial cell lines. This finding was in agreement with the western blot results demonstrating increased expression levels of the ZBTB7A protein in all
CRC cell lines compared with those in the normal colonic epithelial cell lines. We also showed that approximately onethird of the primary CRC tissue samples exhibited positive ZBTB7A expression, and there were significant differences in ZBTB7A immunoreactivity between primary CRC and high-grade dysplasia or normal colonic mucosa samples, indicating that ZBTB7A expression is a potential diagnostic biomarker for CRC. In addition, ZBTB7A overexpression was observed in approximately half of the metastatic CRC tissue samples, with a significant difference in the BTG1 expression between metastatic and primary CRC tissue samples. Overall, our results indicate that $Z B T B 7 A$ upregulation is associated with the development and progression of CRC, highlighting ZBTB7A as a potentially novel therapeutic target for the treatment of patients with CRC.

Our data are consistent with the results of previous studies demonstrating a significant elevation of ZBTB7A expression in carcinomas of various organs. In a study by Zhao and colleagues, the expression levels of ZBTB7A mRNA and protein in CRC tissue were significantly higher than in the adjacent tissues. $Z B T B 7 A$ gene silencing inhibited the proliferation of CRC cells (4). Similarly, Zhu and colleagues have suggested that ZBTB7A promotes cellular proliferation and invasion of CRC cells via enhancing E26 transformation specific proto-oncogene 1 signaling activity (33). Aggarwal and colleagues have observed strong differences in $Z B T B 7 A$ mRNA and protein expression between benign and malignant breast biopsy tissues (9), indicating that ZBTB7A has oncogenic properties and is involved in malignant progression in the breast. Jiao and colleagues also observed that ZBTB7A mRNA and protein expression was significantly higher in nasopharyngeal carcinoma cell lines than in normal nasopharyngeal epithelial cell lines and that nasopharyngeal carcinoma tissues but not chronic rhinitis tissues displayed high levels of ZBTB7A protein expression (34). Moreover, Lin and colleagues have shown that ZBTB7A was markedly expressed in $80.0 \%$ of hepatocellular carcinoma tissues examined, and the expression level was significantly higher in 
hepatocellular carcinoma tissues than in adjacent benign liver tissues, suggesting that ZBTB7A plays an important role in hepatocellular carcinoma development (35). Other data demonstrated that bladder cancer cell lines had a significantly reduced wound-healing capacity and markedly increased Ecadherin level after ZBTB7A was inhibited by RNA interference (36). These findings imply that ZBTB7A may inhibit the expression of E-cadherin, thereby affecting the epithelial-to-mesenchymal transition, and facilitating the progression of bladder cancer. Zhang and colleagues found that ZBTB7A was elevated in cisplatin-resistant osteosarcoma cells, and elevation of ZBTB7A expression inhibitedcisplatininduced apoptosis by repressing the expression of long noncoding RNA LINC00473, indicating that ZBTB7A is an important regulator of chemoresistance in osteosarcoma (37). ZBTB7A has oncogenic activity by transcriptionally repressing the tumor-suppressor alternative reading frame in lymphoma cells and by transcriptionally activating membrane type 1 matrix metalloproteinase in ovarian carcinoma cells $(14,16)$. Taken together, these data suggest that therapeutic targeting of ZBTB7A may potentially be an effective strategy for the treatment of malignancies, including $\mathrm{CRC}$.

On the other hand, ZBTB7A has been demonstrated to exhibit a tumor suppressor function through transcriptional repression of glycolytic genes and melanoma cell adhesion molecule or through indirect inhibition of the sexdetermining region Y-box-containing gene 9-dependent oncogenic pathway (38-41). Deletions and inactivating mutations $(13,38,39)$, as well as suppression by microRNA $(15,41,42)$, have been suggested to contribute to reduced ZBTB7A expression. Liu and colleagues discovered a frequent loss of chromosome $19 \mathrm{p} 13.3$ and associated downregulation of $Z B T B 7 A$ in metastatic melanoma (40). They observed that down-regulation of $Z B T B 7 A$ resulted in marked up-regulation of melanoma cell adhesion molecule and enhanced melanoma cell invasion and metastasis. Consistent with these data, it has been shown that reduced ZBTB7A expression is associated with a poorer prognosis in malignant melanoma, diffuse large B-cell lymphoma, and acute myeloid leukemia, implying a tumor-suppressive role of ZBTB7A (16, 38-40). Thus, the mechanism of ZBTB7A action appears to be versatile, depending on the cell type.

In conclusion, we showed that $Z B T B 7 A$ expression is upregulated in CRC cell lines and tissue samples. The ZBTB7A expression levels in CRC were higher than those in highgrade dysplasia and a normal colonic mucosa. Our data suggest that ZBTB7A is involved in the development and progression of $\mathrm{CRC}$ and can potentially be a diagnostic biomarker for CRC. Significantly higher ZBTB7A expression levels in metastatic CRC than in primary CRC raise the possibility that $Z B T B 7 A$ up-regulation is associated with aggressive oncogenic behavior of CRC. Further studies are necessary to confirm our results from this study.

\section{Acknowledgements}

This research was supported by the Basic Science Research Program through the National Research Foundation of Korea (NRF) funded by the Ministry of Science, ICT and Future Planning (2017R1A2B4007704) and by the Ministry of Education (2016R1D1A1B03935584).

\section{References}

1 Jemal A, Siegel R, Ward E, Murray T, Xu J and Thun MJ: Cancer statistics, 2007. CA Cancer J Clin 57: 43-66, 2007.

2 Misiakos EP, Karidis NP and Kouraklis G: Current treatment for colorectal liver metastases. World J Gastroenterol 17: 40674075, 2011.

3 Jung KW, Won YJ, Kong HJ, Oh CM, Cho H, Lee DH and Lee KH: Cancer statistics in Korea: incidence, mortality, survival, and prevalence in 2012. Cancer Res Treat 47: 127-141, 2015.

4 Zhao GT, Yang LJ, Li XX, Cui HL and Guo R: Expression of the proto-oncogene Pokemon in colorectal cancer - inhibitory effects of an siRNA. Asian Pac J Cancer Prev 14: 4999-5005, 2013.

5 Sung JY, Na K and Kim HS: Down-regulation of inositol polyphosphate 4-phosphatase type II expression in colorectal carcinoma. Anticancer Res 37: 5525-5531, 2017.

6 Lee SU and Maeda T: POK/ZBTB proteins: an emerging family of proteins that regulate lymphoid development and function. Immunol Rev 247: 107-119, 2012.

7 Lunardi A, Guarnerio J, Wang G, Maeda T and Pandolfi PP: Role of LRF/Pokemon in lineage fate decisions. Blood 121: 2845-2853, 2013.

8 Morrison DJ, Pendergrast PS, Stavropoulos P, Colmenares SU, Kobayashi R and Hernandez N: FBI-1, a factor that binds to the HIV-1 inducer of short transcripts (IST), is a POZ domain protein. Nucleic Acids Res 27: 1251-1262, 1999.

9 Aggarwal A, Hunter WJ, 3rd, Aggarwal H, Silva ED, Davey MS, Murphy RF and Agrawal DK: Expression of leukemia/ lymphoma-related factor (LRF/POKEMON) in human breast carcinoma and other cancers. Exp Mol Pathol 89: 140-148, 2010.

10 Aggarwal H, Aggarwal A, Hunter WJ, 3rd, Yohannes P, Khan AU and Agrawal DK: Expression of leukemia/lymphoma related factor (LRF/Pokemon) in human benign prostate hyperplasia and prostate cancer. Exp Mol Pathol 90: 226-230, 2011.

11 Pendergrast PS, Wang C, Hernandez N and Huang S: FBI-1 can stimulate HIV-1 TAT activity and is targeted to a novel subnuclear domain that includes the TAT-P-TEFb-containing nuclear speckles. Mol Biol Cell 13: 915-929, 2002.

12 Zhao Z-h, Wang S-f, Yu L, Wang J, Chang H, Yan W-l, Zhang J and $\mathrm{Fu} \mathrm{K}$ : Overexpression of Pokemon in non-small cell lung cancer and foreshowing tumor biological behavior as well as clinical results. Lung Cancer 62: 113-119, 2008.

13 Liu XS, Liu Z, Gerarduzzi C, Choi DE, Ganapathy S, Pandolfi PP and Yuan ZM: Somatic human ZBTB7A zinc finger mutations promote cancer progression. Oncogene 35: 3071-3078, 2016.

14 Jiang L, Siu MK, Wong OG, Tam KF, Lam EW, Ngan HY, Le $\mathrm{XF}$, Wong ES, Chan HY and Cheung AN: Overexpression of proto-oncogene FBI-1 activates membrane type 1-matrix metalloproteinase in association with adverse outcome in ovarian cancers. Mol Cancer 9: 318, 2010. 
15 Shi DB, Wang YW, Xing AY, Gao JW, Zhang H, Guo XY and Gao P: C/EBPalpha-induced miR-100 expression suppresses tumor metastasis and growth by targeting ZBTB7A in gastric cancer. Cancer Lett 369: 376-385, 2015.

16 Maeda T, Hobbs RM, Merghoub T, Guernah I, Zelent A, Cordon-Cardo C, Teruya-Feldstein J and Pandolfi PP: Role of the proto-oncogene Pokemon in cellular transformation and ARF repression. Nature 433: 278-285, 2005.

17 Livak KJ and Schmittgen TD: Analysis of relative gene expression data using real-time quantitative PCR and the $2-\Delta \Delta \mathrm{Ct}$ Method. Methods 25: 402-408, 2001.

$18 \mathrm{Kim}$ HS, Yoon G, Do SI, Kim SJ and Kim YW: Downregulation of osteoprotegerin expression as a novel biomarker for colorectal carcinoma. Oncotarget 7: 15187-15199, 2016.

19 Moon A, Do SI, Kim HS and Kim YW: Down-regulation of osteoprotegerin expression in metastatic colorectal carcinoma predicts recurrent metastasis and poor prognosis. Oncotarget 7 : 79319-79326, 2016.

20 Kim HS, Do SI, Noh BJ, Jeong YI, Park SJ and Kim YW: Expression of phosphorylated extracellular signal-regulated kinase at the invasive front of hepatic colorectal metastasis. Oncol Lett 9: 1261-1265, 2015.

21 Kim HS, Park SJ, Lee KY, Park YK and Kim YW: Reduced RAF-1 kinase inhibitor protein expression predicts less favorable outcomes in patients with hepatic colorectal metastasis. Oncol Rep 28: 161-171, 2012.

22 Do SI, Yoon G, Kim HS, Kim K, Lee H, Do IG, Kim DH, Chae SW and Sohn JH: Increased Brahma-related gene 1 expression predicts distant metastasis and shorter survival in patients with invasive ductal carcinoma of the breast. Anticancer Res 36: 4873-4882, 2016.

23 Yoon N, Yoon G, Park CK and Kim HS: Stromal p16 expression is significantly increased in malignant ovarian neoplasms. Oncotarget 7: 64665-64673, 2016.

24 Yoon G, Koh CW, Yoon N, Kim JY and Kim HS: Stromal p16 expression is significantly increased in endometrial carcinoma. Oncotarget 8: 4826-4836, 2017.

$25 \mathrm{Na} \mathrm{K}$ and Kim HS: Clinicopathologic and molecular characteristics of mesonephric adenocarcinoma arising from the uterine body. Am J Surg Pathol, 2017. doi: 10.1097/ PAS.0000000000000991. [Epub ahead of print]

26 Do SI, Kim HS, Kim K, Lee H, Do IG, Kim DH, Chae SW and Sohn JH: Predictive value of sphingosine kinase 1 expression in papillary thyroid carcinoma. Anticancer Res 37: 5399-5405, 2017.

27 Jang MI, Sung JY, Kim JY and Kim HS: Clinicopathological characteristics of metaplastic papillary tumor of the fallopian tube. Anticancer Res 37: 3693-3701, 2017.

28 Jung YY, Sung JY, Kim JY and Kim HS: Down-regulation of Bcell translocation gene 1 by promoter methylation in colorectal carcinoma. Anticancer Res 38: 691-697, 2018.

$29 \mathrm{Na} \mathrm{K}$ and Kim HS: Clinicopathological characteristics of fallopian tube metastases from primary endometrial, cervical, and nongynecological malignancies: a single institutional experience. Virchows Arch 471: 363-373, 2017.

30 Kekelidze M, D'Errico L, Pansini M, Tyndall A and Hohmann J: Colorectal cancer: current imaging methods and future perspectives for the diagnosis, staging and therapeutic response evaluation. World J Gastroenterol 19: 8502-8514, 2013.

31 Zafar SY, Malin JL, Grambow SC, Abbott DH, Kolimaga JT, Zullig LL, Weeks JC, Ayanian JZ, Kahn KL, Ganz PA, Catalano PJ, West DW and Provenzale D: Chemotherapy use and patient treatment preferences in advanced colorectal cancer: a prospective cohort study. Cancer 119: 854-862, 2013.

32 Edge SB, Byrd DR, Compton CC, Fritz AG, Greene FL and Trotti A: AJCC Cancer Staging Manual. New York, NY, USA: Springer, 2010.

33 Zhu M, Li M, Zhang F, Feng F, Chen W, Yang Y, Cui J, Zhang D and Linghu E: FBI-1 enhances ETS-1 signaling activity and promotes proliferation of human colorectal carcinoma cells. PLoS One 9: e98041, 2014.

34 Jiao W, Liu F, Tang FZ, Lan J, Xiao RP, Chen XZ, Ye HL and Cai YL: Expression of the Pokemon proto-oncogene in nasopharyngeal carcinoma cell lines and tissues. Asian Pac J Cancer Prev 14: 6315-6319, 2013.

35 Lin CC, Zhou JP, Liu YP, Liu JJ, Yang XN, Jazag A, Zhang ZP, Guleng B and Ren JL: The silencing of Pokemon attenuates the proliferation of hepatocellular carcinoma cells in vitro and in vivo by inhibiting the PI3K/AKT pathway. PLoS One 7: e51916, 2012.

36 Guo C, Zhu K, Sun W, Yang B, Gu W, Luo J, Peng B and Zheng $\mathrm{J}$ : The effect of Pokemon on bladder cancer epithelialmesenchymal transition. Biochem Biophys Res Commun 443: 1226-1231, 2014.

37 Zhang L, Wang Y, Li X, Xia X, Li N, He R, He H, Han C and Zhao W: ZBTB7A Enhances osteosarcoma chemoresistance by transcriptionally repressing lncRNALINC00473-IL24 activity. Neoplasia 19: 908-918, 2017.

38 Liu XS, Haines JE, Mehanna EK, Genet MD, Ben-Sahra I, Asara JM, Manning BD and Yuan ZM: ZBTB7A acts as a tumor suppressor through the transcriptional repression of glycolysis. Genes Dev 28: 1917-1928, 2014.

39 Hartmann L, Dutta S, Opatz S, Vosberg S, Reiter K, Leubolt G, Metzeler KH, Herold T, Bamopoulos SA, Braundl K, Zellmeier E, Ksienzyk B, Konstandin NP, Schneider S, Hopfner KP, Graf A, Krebs S, Blum H, Middeke JM, Stolzel F, Thiede C, Wolf S, Bohlander SK, Preiss C, Chen-Wichmann L, Wichmann C, Sauerland MC, Buchner T, Berdel WE, Wormann BJ, Braess J, Hiddemann W, Spiekermann K and Greif PA: ZBTB7A mutations in acute myeloid leukaemia with $\mathrm{t}(8 ; 21)$ translocation. Nat Commun 7: 11733, 2016.

40 Liu XS, Genet MD, Haines JE, Mehanna EK, Wu S, Chen HI, Chen Y, Qureshi AA, Han J, Chen X, Fisher DE, Pandolfi PP and Yuan ZM: ZBTB7A suppresses melanoma metastasis by transcriptionally repressing MCAM. Mol Cancer Res 13: 1206$1217,2015$.

41 Wang G, Lunardi A, Zhang J, Chen Z, Ala U, Webster KA, Tay Y, Gonzalez-Billalabeitia E, Egia A, Shaffer DR, Carver B, Liu XS, Taulli R, Kuo WP, Nardella C, Signoretti S, Cordon-Cardo C, Gerald WL and Pandolfi PP: ZBTB7A suppresses prostate cancer through repression of a SOX9-dependent pathway for cellular senescence bypass and tumor invasion. Nat Genet 45: 739-746, 2013.

42 Hojo N, Tatsumi N, Moriguchi N, Matsumura A, Morimoto S, Nakata J, Fujiki F, Nishida S, Nakajima H, Tsuboi A, Oka Y, Hosen N, Hayashi S, Sugiyama H and Oji Y: A ZBTB7A protooncogene as a novel target for miR-125a. Mol Carcinog 55: 2001-2009, 2016.

Received February 17, 2018

Revised March 7, 2018

Accepted March 8, 2018 